\title{
Determining the total energy budget of the tick Ixodes ricinus
}

\author{
Saeed Alasmari ${ }^{1} \cdot$ Richard Wall $^{1}$ \\ Received: 12 November 2019 / Accepted: 6 March 2020 / Published online: 13 March 2020 \\ (c) The Author(s) 2020
}

\begin{abstract}
Precise and accessible techniques for measuring metabolic responses to environmental stress are essential to allow the likely impacts of climate and climate change on tick distribution, abundance and phenology to be predicted. A more detailed understanding of the metabolic profile of ticks may also help the complex responses to pathogen infection and effects on transmission to be evaluated. Here, a series of biochemical protocols employing spectrophotometric methods are used to determine the entire energy budget of ticks. Protein, carbohydrate, total lipid, neutral lipid and glycogen were measured in individual Ixodes ricinus nymphs and adults. Two key trends were identified: in adults, protein was relatively more abundant than in nymphs, whereas in nymphs, glycogen and carbohydrate were more abundant than in adults, with glycogen alone composing $39 \%$ of the mass of metabolites in nymphs compared to 15 and $10 \%$ in females and males, respectively. The methods used were able to successfully separate neutral lipids from the polar phospholipids and the importance of distinguishing stored from structural lipid in estimates of lipid reserves is emphasised. The results demonstrate that the spectrophotometric approaches deliver relatively rapid and reliable estimates of the total energetic budget and can be used to quantify the metabolic profiles of individual ticks, demonstrating their suitability for use in ecological and epidemiological studies.
\end{abstract}

Keywords Carbohydrate $\cdot$ Glycogen $\cdot$ Lipid $\cdot$ Metabolism $\cdot$ Protein $\cdot$ Resource acquisition

\section{Introduction}

For multi-host ixodid ticks, the blood meal obtained by each lifecycle stage must provide the resource required for development and/or reproduction (Sonenshine and Roe 2014). Between feeding events, ticks spend the majority of their lives off the host where they need to survive adverse environmental conditions (Needham and Teel 1991). To facilitate survival during these extended inter-feed intervals and then ensure that sufficient stored resources are available to allow repeated questing until a host is located, ixodid ticks have a metabolic rate which is typically 13\% below that of most arthropods (Lighton and Fielden 1995). Given this intermittent 'high-risk' sit-and-wait feeding strategy, understanding how

Saeed Alasmari

sa16081@bristol.ac.uk

1 School of Biological Sciences, University of Bristol, 24 Tyndall Avenue, Bristol BS8 1TQ, UK 
ticks partition resources between maintenance, development, reproduction and storage for future requirements is of intrinsic physiological interest but their measurement can also allow insight into the feeding history and ecology of cohorts of field-derived ticks (Randolph et al. 2002; Abdullah et al. 2018) and can allow predictions about the likely impact of changes in rate determining environmental factors such as temperature and humidity (Randolph et al. 2002; Rosendale et al. 2017).

The main immediate source of energy for ticks is glucose, which is stored in a hydrated polymeric form as glycogen. Glycogen serves as an energy source to support the post-feeding stage, but is rapidly depleted (Moraes et al. 2007). Metabolism of glycogen involves its breakdown to glucose with resultant energy release. Carbohydrate can be used to replenish glycogen reserves so that energy is available for activity. Lipids also play key roles in tick metabolism, both as an energy source and structurally in cell membranes, in hormones and for egg development (Kluck et al. 2018). Lipid is stored primarily the form of triglycerides in adipocytes the main fat body cell and additionally as cytoplasmic lipid droplets. Storage is mostly regulated by hormones in response to physiological demands; in insects marked decreases in lipid content have been associated with key growth phases (Arrese and Soulages 2010). Lipids measured as a total concentration (stored lipids such as triglyceride plus structural lipids present in cell membranes) are commonly used as proxy for stored lipids to give an indication of energy reserves (Abdullah et al. 2018). However, only the stored lipids are functionally valuable as an energy reserve and consideration of total lipid alone may be misleading because the dominant triglyceride component fluctuates considerably with developmental stage, sex and even season and may vary independently of other lipid classes, such as diglyceride, monoglyceride, sterols, sterol esters, free fatty acids and pholipids (Angelo et al. 2013). Hence, accurate distinction between structural polar lipids and total lipids may be important. Finally, proteins are important and may act as a longterm energy reserve (Williams et al. 1986) and are structurally essential for muscle, cuticle synthesis, hormones, enzymes, carrier proteins (Kluck et al. 2018), in females for the synthesis of egg yolk (Tatchell 1971; Xavier et al. 2019) and in males for sperm and gonadal proteins that trigger engorgement in females (Weiss and Kaufman 2004). Glycogen resynthesis by protein degradation through the gluconeogenesis pathway has been demonstrated in ticks, notably at the end of the embryonic period (Martins et al. 2018).

The measurement of energy budgets and the factors affecting metabolic rate have been well studied in insects (Chown and Nicolson 2004) and approaches using spectrophotometric techniques, as developed by Van Handel (1985a, b), have been used widely for such measurements (Raubenheimer et al. 2009), for example allowing insect nutrient levels to be related to egg load or longevity (Otronen 1995), or to allow explanations of insect population dynamics and behavioural ecology in terms of resource availability (Pelosse et al. 2007). Such studies have looked in particular at the measurement of lipids, but the analytical approaches have also been extended to allow the estimation of glycogen and free sugars. These analytical methods are used increasingly because they are relatively inexpensive, rapid and precise. However, although applied extensively in insects, these techniques have rarely been used in ticks (Abdullah et al. 2018).

The aim of the work described here, therefore, was to evaluate the use of the range of spectrophotometric techniques for quantifying protein, carbohydrate, lipid and glycogen resources in ticks in the nymphal and adult life-cycle stages. A further aim was to explore the separate quantification of neutral lipids and structural polar phospholipids to allow more exact quantification of the contribution of lipids to energy reserves. In particular, the work aimed to determine whether several metabolites could be determined for an individual tick. To explore this, two analytical approaches were compared. The first applied 
multiple biochemical measurements to individual ticks, whereas the second, used separate ticks for the measurement of complimentary groups of metabolites.

\section{Material and methods}

\section{Sample collection}

Ixodes ricinus ticks (nymphs, males and females) were collected every 2 weeks from the field between March to May in 2017 by blanket-dragging. The field site was a semi-urban park $\left(51^{\circ} 26^{\prime} 49.2^{\prime \prime} \mathrm{N}, 2^{\circ} 38^{\prime} 01.9^{\prime \prime} \mathrm{W}\right)$ to the west of the city of Bristol in southwest England, containing managed herds of red and fallow deer and a population of wild roe deer and where ticks are abundant (Jennett et al. 2013). The ticks collected were identified to species, sex and lifecycle stage using standard keys (Arthur 1963; Hillyard 1996; Walker et al. 2014). They were weighed using an ultrasensitive microbalance (Sartorius-ME5, Goettingen, Germany) to the nearest microgram and then stored at $-20{ }^{\circ} \mathrm{C}$ for a maximum of 8 weeks prior to analysis.

The ticks collected were divided at random into two groups based on the analytical approach to be used. In the first group, referred to as the 'individual-analysis' group, a total of 60 ticks were used, 30 for protein analysis and 30 for the measurement of all other metabolites in each specimen. In the second, referred to as the 'multi-analysis' group, in total 90 ticks were used, 30 for protein analysis, 30 for both free sugars and glycogen and 30 for total lipids and neutral lipids. In all cases, each group of 30 ticks consisted of 10 nymphs, 10 males and 10 females.

\section{Individual analysis ticks}

Protein was measured following the method described by Bradford (1976). Ticks were first placed individually into a clean borosilicate tube $(12 \mathrm{ml})$ and crushed using a clean glass rod. This was followed by the addition of $1500 \mu \mathrm{l}$ of phosphate buffer solution to extract the protein $(100 \mathrm{mM}$ of monopotassium phosphate, $1 \mathrm{mM}$ of ethylenediaminetetraacetic acid (EDTA) and $1 \mathrm{mM}$ of dithiothreitol (DTT), $\mathrm{pH}$ 7.4). Thereafter, the homogenate was placed on ice prior to processing (about $1 \mathrm{~min}$ ). For nymphs, $1000 \mu \mathrm{l}$ was transferred to a cuvette and mixed with $1000 \mu \mathrm{l}$ of Bradford reagent (Sigma, Dorset, UK). For males and females, $50 \mu \mathrm{l}$ was transferred to a cuvette and mixed with $1500 \mu \mathrm{l}$ of Bradford reagent. Individual cuvettes were incubated at room temperature for $5 \mathrm{~min}$ and then the absorbance value was immediately measured at a wavelength of $595 \mathrm{~nm}$ using a Biochrome spectrophotometer (Biowave II, Cambridge, UK). The procedure is based on the formation of a protein-dye complex; coomassie dye in the Bradford reagent binds with proteins and results in a change in colour from brown to blue leading to a shift in the absorption maximum from 465 to $595 \mathrm{~nm}$.

For analysis of other metabolites, a single individual tick was placed into a clean borosilicate tube and crushed, as above. To dissolve all water-soluble carbohydrates and the total fats, $200 \mu \mathrm{l}$ of $2 \%$ sodium sulphate solution (VWR International, Leicestershire, $\mathrm{UK})$, and $1500 \mu \mathrm{l}$ of a chloroform/methanol mixture (1:2 vol/vol) were added to each tube. This mixture was then transferred into a $2 \mathrm{ml}$ Eppendorf tube and centrifuged (Centrifuge 5418R; Eppendorf Lutterworth, UK) for $15 \mathrm{~min}$ at $180 \times \mathrm{g}$ and $4{ }^{\circ} \mathrm{C}$. For total lipid, neutral 
lipid and carbohydrate analysis, the supernatant was removed into a new tube; and the pellets containing glycogen were retained for further analysis.

Beginning with carbohydrate determination, the method of Van Handel (1965) was used. $200 \mu \mathrm{l}$ of the supernatant from individual samples were moved into a borosilicate tube and placed in a water bath at $90{ }^{\circ} \mathrm{C}$ for $40 \mathrm{~s}$ to evaporate the solvent to about $20 \mu \mathrm{l}$. Thereafter, $1 \mathrm{ml}$ of freshly prepared anthrone reagent (Sigma) $(1.42 \mathrm{~g} / 1 \mathrm{in} 70 \%$ sulphuric acid; VWR International) was added to each sample and incubated for $15 \mathrm{~min}$ at $25{ }^{\circ} \mathrm{C}$. Subsequently, the tubes were heated for $15 \mathrm{~min}$ at $90{ }^{\circ} \mathrm{C}$ and then cooled at room temperature for $15 \mathrm{~min}$, after which the samples were placed in microcuvette and finally read in a spectrophotometer set at $625 \mathrm{~nm}$, to determine the total water-soluble carbohydrates. Blue green coloration indicates the binding of anthrone to sugar.

For glycogen determination, pellets were washed on two occasions using $400 \mu \mathrm{l}$ of $80 \%$ methanol to remove sodium sulphate. Vigorous vortexing was followed by centrifugation, for $5 \mathrm{~min}$ at $180 \times \mathrm{g}$ at $4{ }^{\circ} \mathrm{C}$. Once the supernatant was eliminated, $1 \mathrm{ml}$ of fresh anthrone reagent was added and the mixture was incubated at $90{ }^{\circ} \mathrm{C}$ for $15 \mathrm{~min}$. Each sample was cooled on ice to end the reaction and filtered on low-protein binding membranes of diameter $0.45 \mu \mathrm{m}$ (Fisher Scientific, Leicestershire, UK). Finally, the absorbance was read in a spectrophotometer at $625 \mathrm{~nm}$ to quantify the presence of water-soluble carbohydrates.

The total lipids were quantified using a vanillin assay. For this, $200 \mu \mathrm{l}$ of the supernatant was added into a new borosilicate tube and placed into a heating block at $90{ }^{\circ} \mathrm{C}$ until total evaporation was achieved. $40 \mu \mathrm{l}$ of $95 \%$ sulphuric acid (VWR International), was added to the mixture and heated at $90{ }^{\circ} \mathrm{C}$ for $2 \mathrm{~min}$ and then cooled in ice. $960 \mu \mathrm{l}$ of freshly prepared $1.2 \mathrm{~g} / \mathrm{l}$ vanillin reagent (Fisher Scientific) in 68\% phosphoric acid (Sigma) was added and followed by incubation at room temperature for $15 \mathrm{~min}$. The absorbance was read in a spectrophotometer at $525 \mathrm{~nm}$ (Van Handel 1985b). Finally, the neutral lipid content was measured by placing $500 \mu \mathrm{l}$ of the supernatant in a new tube, which was heated at $90{ }^{\circ} \mathrm{C}$ to evaporate off the solvents. One $1 \mathrm{ml}$ of chloroform was added into each tube to re-solubilize the fats. $200 \mathrm{mg}$ of dry silicic acid (Sigma) was added to each sample. Thereafter, all samples were mixed and then centrifuged at $180 \times g$ and $4{ }^{\circ} \mathrm{C}$ for $10 \mathrm{~min}$ to remove polar lipids in the silicic acid. From the final supernatant $200 \mu \mathrm{l}$ was pipetted off and removed into new tube. Again, the absorbance was read in a spectrophotometer at $525 \mathrm{~nm}$ (Van Handel 1985b).

\section{Multi-analysis ticks}

For multi-analysis, 30 ticks were used for protein analysis, as described above. Thirty ticks were used for the analysis of carbohydrate and glycogen only and a further 30 were used only for the analysis of lipids, following the procedures described above.

\section{Standard curves}

Standard curves of absorbance against known metabolite concentration were created to allow spectrophotometric values to be related to metabolite concentrations. Care was taken to ensure linearity within the various concentrations and that they started below the lowest sample value and ended beyond the highest. For protein concentration a standard curve was generated with a dilution series of bovine serum albumin (BSA) $(1 \mathrm{mg} / \mathrm{ml}$ ) (Sigma) treated as described above. For carbohydrate and glycogen, a standard curve was generated using glucose $(1 \mathrm{mg} / \mathrm{ml})$ (Sigma) at a range of dilutions. For lipids a standard curve was 
generated using glycerol trioleate $(1 \mathrm{mg} / \mathrm{ml})$ (Sigma) at various dilutions. Five independent repeats of different serial dilutions were conducted to produce each standard curve.

\section{Statistical analysis}

Generalized linear models (with a gamma distribution and inverse link) with Tukey multiple comparisons post-hoc tests were used to compare the mass of different metabolites within each lifecycle stage and the masses of metabolites measured using the individualanalysis or multiple-analysis approaches and the weights of ticks included in the two analysis-groups. One-way ANOVA was used to compare tick body weights between analysisgroups. All analyses were performed with the R-Studio statistical package (R v.3.5.3, 2019, $\mathrm{R}$ Foundation for Statistical Computing, Vienna, Austria). For graphical presentation of the metabolite data, medians are plotted with $95 \%$ confidence intervals.

\section{Results}

All the ticks collected from the field were I. ricinus. The mean $( \pm \mathrm{SE})$ body mass of nymphs, males and females used in the individual analysis was $0.138( \pm 0.006), 0.884$ $( \pm 0.034)$ and $1.649( \pm 0.069) \mathrm{mg}$, whereas the means of the weights of these lifecycle stages in the multi-analysis groups were $0.130( \pm 0.004), 0.843( \pm 0.022)$ and 1.634 $( \pm 0.006) \mathrm{mg}$, respectively. Within each lifecycle stage these weights were not significantly different from each other (nymphs: $\mathrm{F}_{1,149}=1.44, \mathrm{P}=0.23$; males: $\mathrm{F}_{1,149}=1.14, \mathrm{P}=0.29$; females: $F_{1,149}=0.03, P=0.86$ ). Statistical analysis showed that there were no significant differences between the individual- or multi-analysis methods in any of the metabolite concentrations recorded in nymphs, males or females (Table 1) and data were therefore pooled for subsequent analysis.

In nymphs, the metabolite contents show a significant difference between the amounts of different categories present $\left(\mathrm{F}_{4,45}=12.31, \mathrm{P}<0.001\right)$. Glycogen was the most abundant metabolite with a median of $0.014 \mathrm{mg}$ and was significantly more abundant than any other metabolite. Protein was the second most abundant metabolite, with a high degree of

Table 1 Statistical comparison of the mass of phospholipid, neutral lipid, carbohydrate and glycogen values recorded in nymphs, males and females of Ixodes ricinus $(\mathrm{n}=30$ in each case), where all were measured either in a single individual or where lipids and glycogen/carbohydrate were measured separately in different groups

\begin{tabular}{llll}
\hline Metabolite category & Lifecycle stages & F & P \\
\hline Phospholipid & Nymphs & 1.90 & 0.28 \\
& Males & 1.03 & 0.35 \\
Femalral lipids & Nymphs & 1.73 & 0.24 \\
& Males & 0.76 & 0.41 \\
Carbohydrate & Females & 1.24 & 0.31 \\
& Nymphs & 0.21 & 0.66 \\
& Males & 0.69 & 0.43 \\
Glycogen & Females & 7.79 & 0.15 \\
& Nymphs & 0.34 & 0.56 \\
& Males & 6.53 & 0.22 \\
& Females & 4.81 & 0.43 \\
\hline
\end{tabular}

$\mathrm{F}$ and $\mathrm{P}$ values are based on a generalised linear model (GLM) 
consistency between individuals. Total lipid and neutral lipid concentrations were low as was the median concentration of carbohydrate, but the latter was notable for its very high degree of variation between individuals (Fig. 1).

In adults, there were significant differences in the amounts of the different categories of nutrient present, in males $\left(\mathrm{F}_{4,45}=172, \mathrm{P}<0.001\right)$ and females $\left(\mathrm{F}_{4,45}=196.8, \mathrm{P}<0.001\right)$. Males had high median values for protein, at $0.056 \mathrm{mg}$, which was significantly greater than other metabolites, which had concentrations that were not significantly different from each other. The degree of variation around the median values was consistently relatively small (Fig. 2). Females also had concentrations of protein which were relatively high and similar to those of males (Fig. 3). They had low concentrations of lipid, both total lipid and neutral lipid, but they had concentrations of carbohydrate and glycogen at around $0.3 \mathrm{mg}$, which were considerably greater than those seen in males (Fig. 3).

Consideration of the amounts of each metabolite present as a percentage, to allow for comparison between lifecycle stages, shows that the greatest differences in metabolite concentrations between nymphal and adult stages were in protein and glycogen (Fig. 4). In nymphs, glycogen accounted for $39 \%$ of the metabolites measured, whereas protein accounted for $25 \%$. However, in males and females the protein values were at 60 and $53 \%$, respectively, whereas the glycogen contents were lower at 12 and $19 \%$, respectively. Other

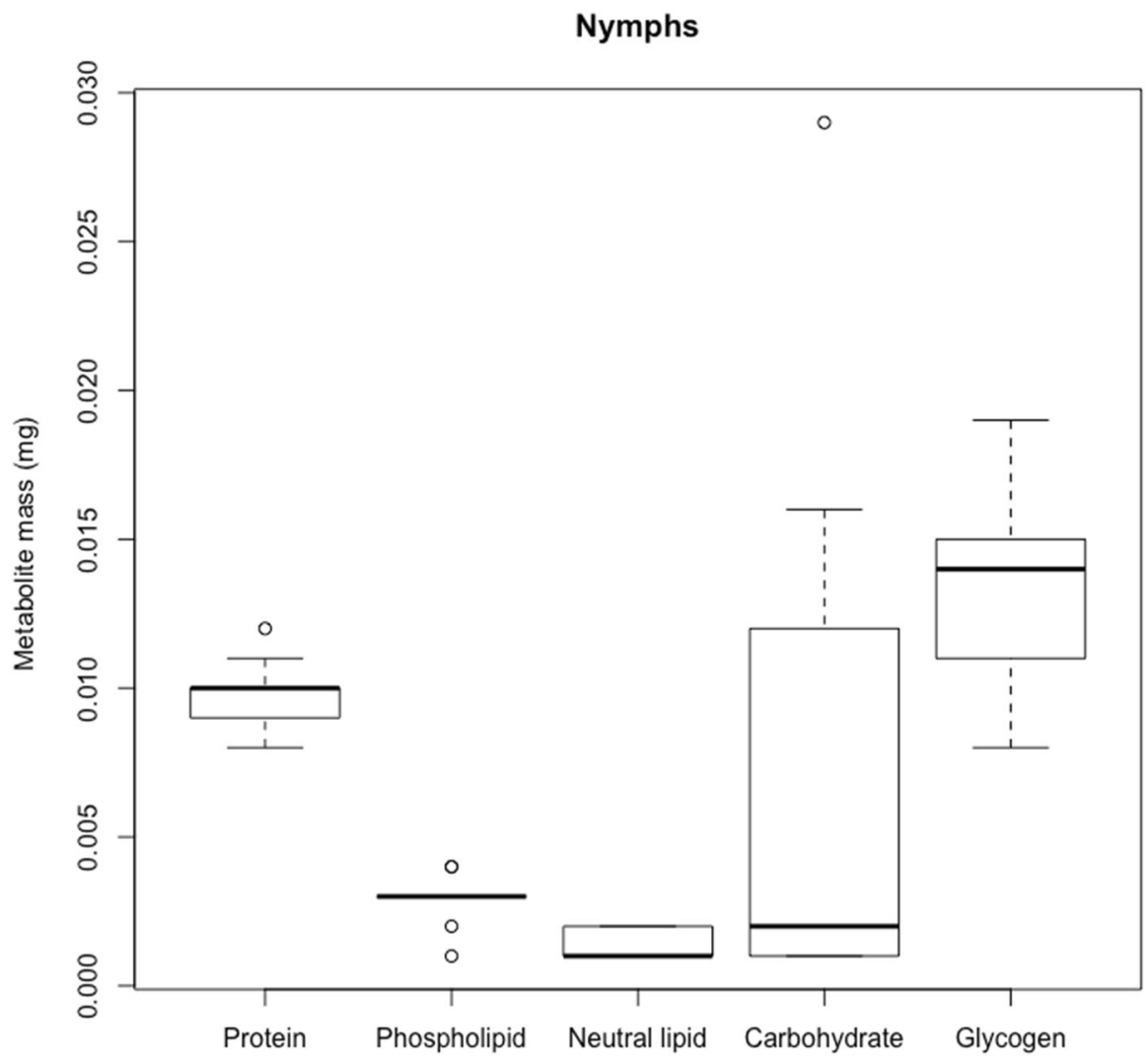

Fig. 1 The median mass of five metabolites (mg) in Ixodes ricinus nymphs with 95\% confidence interval (dashed lines) and lower and upper quartiles (box) 


\section{Males}

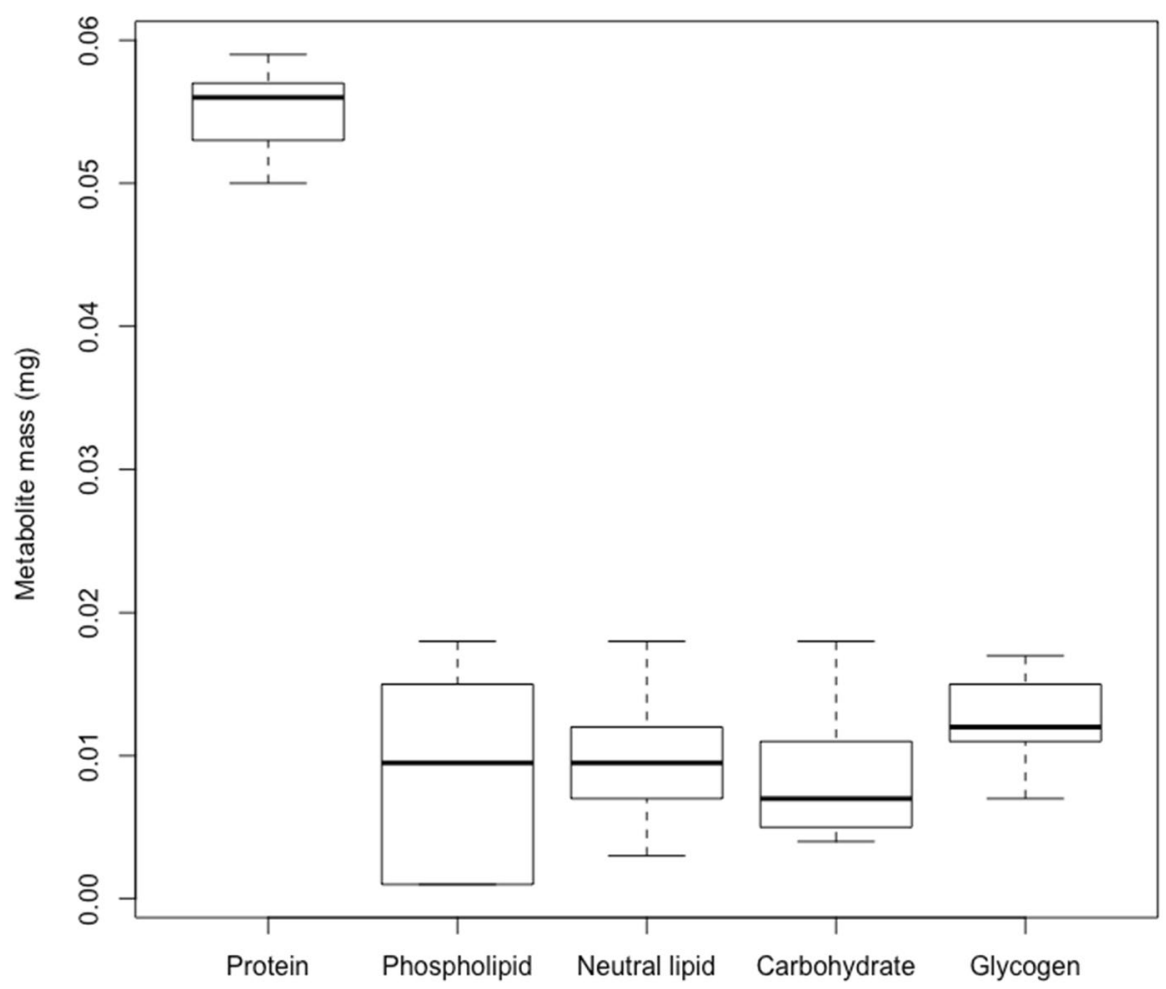

Fig. 2 The median mass of five metabolites (mg) in Ixodes ricinus males with $95 \%$ confidence interval (dashed lines) and lower and upper quartiles (box)

metabolites were relatively similar between lifecycle stages. Notably lipid was consistently the least abundant metabolite.

The methods used were able successfully to separate neutral lipids from the polar lipids; about $94.6 \%$ of polar lipid was extracted from the standardized phospholipid solution. In nymphs, $8.4 \%$ of the mass was composed of lipids of which neutral lipids represented 45.2\%. In adults, total lipid composed about 10 and $5 \%$ of the total body mass in males and females, respectively, whereas neutral lipids composed about $85 \%$ of the lipid fraction in males and about $96 \%$ in females (Fig. 4).

\section{Discussion}

Ticks need to be able to survive for extended periods between blood meals. During these off-host periods, they need to endure adverse conditions and maintain sufficient reserves to allow repeated episodes of host-seeking behaviour. Starvation of ticks for 18 or 36 weeks, in the absence of dehydration, was shown to result in the loss of $20-40 \%$ of protein and $60 \%$ of lipid reserves in the American dog tick, Dermacentor variabilis (Rosendale et al. 2017). The lipid reserves of field-collected I. ricinus ticks, collected in early summer, 


\section{Females}

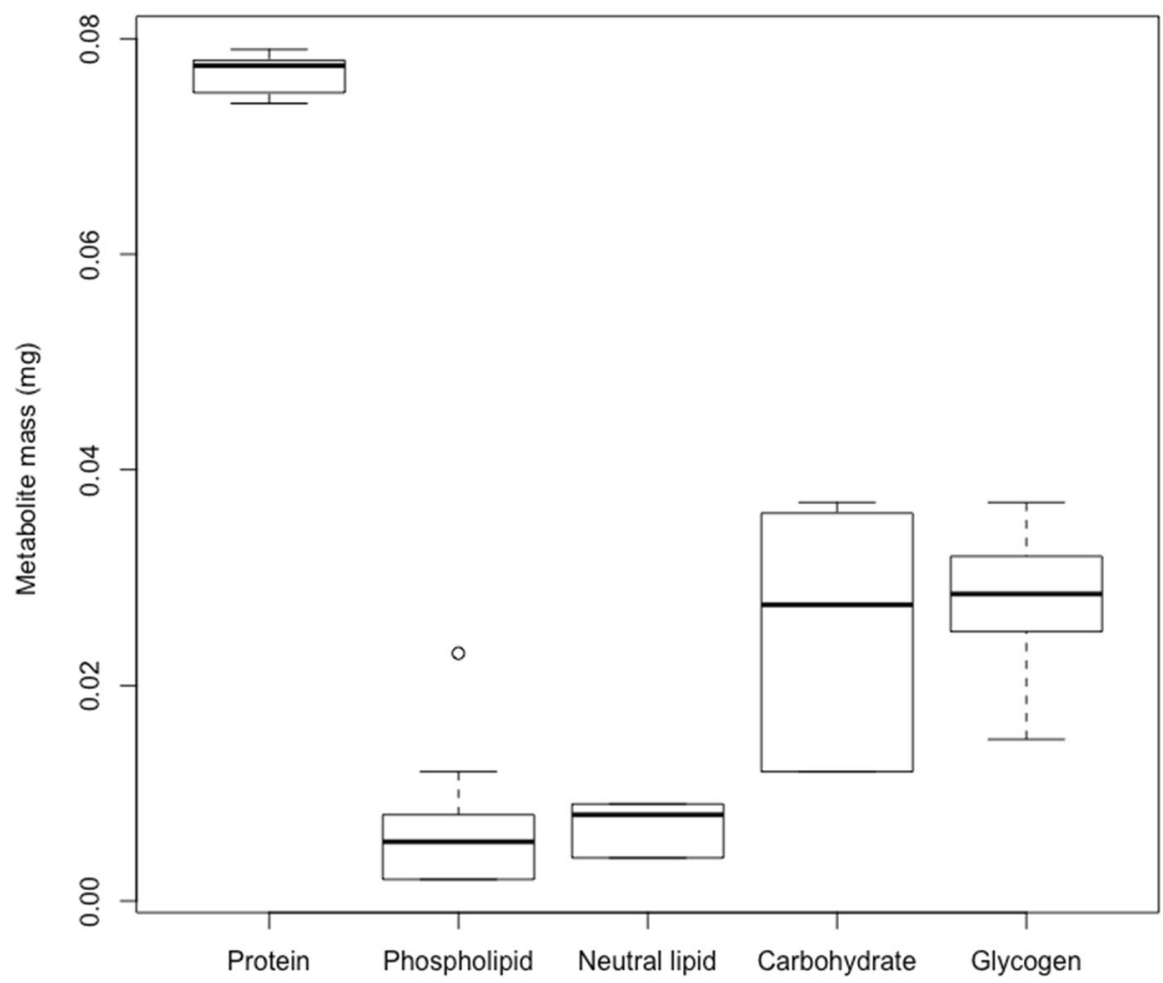

Fig. 3 The median mass of five metabolites (mg) in Ixodes ricinus females with $95 \%$ confidence interval (dashed lines) and lower and upper quartiles (box)

were estimated to be sufficient to allow survival without feeding for up to 100-250 days at $15{ }^{\circ} \mathrm{C}$, depending on whether they had fed the previous autumn or that year, respectively (Abdullah et al. 2018).

The pattern of metabolic activity is not constant. A newly moulted tick is able to maintain relatively low levels of activity and minimise energy expenditure for several weeks; but once energy levels start to become depleted the level of activity and consequently energy expenditure may rise as questing activity becomes more prolonged and persistent. This may increase their susceptibility to environmental stresses such as dehydration (Rosendale et al. 2017). A significant increase in energy use has been associated with ovary development in female ticks (Xavier 2019). A detailed understanding of the patterns of changing resource within ticks would therefore be expected to provide information in field-collected cohorts about their metabolic rate, feeding history and questing activity.

Early approaches to examining metabolic reserves used histological or anatomical examination of ixodid ticks to categorise them into feeding cohorts, but such approaches are relatively imprecise (Uspensky 1995; Walker 2001). Subsequently spectrophotometric methods have been used to examine total lipid (Abdullah et al. 2018), and the current paper extends these approaches to a consideration of the full metabolic profile in the tick I. ricinus. These methods have been used widely in insects, but have not previously been used 


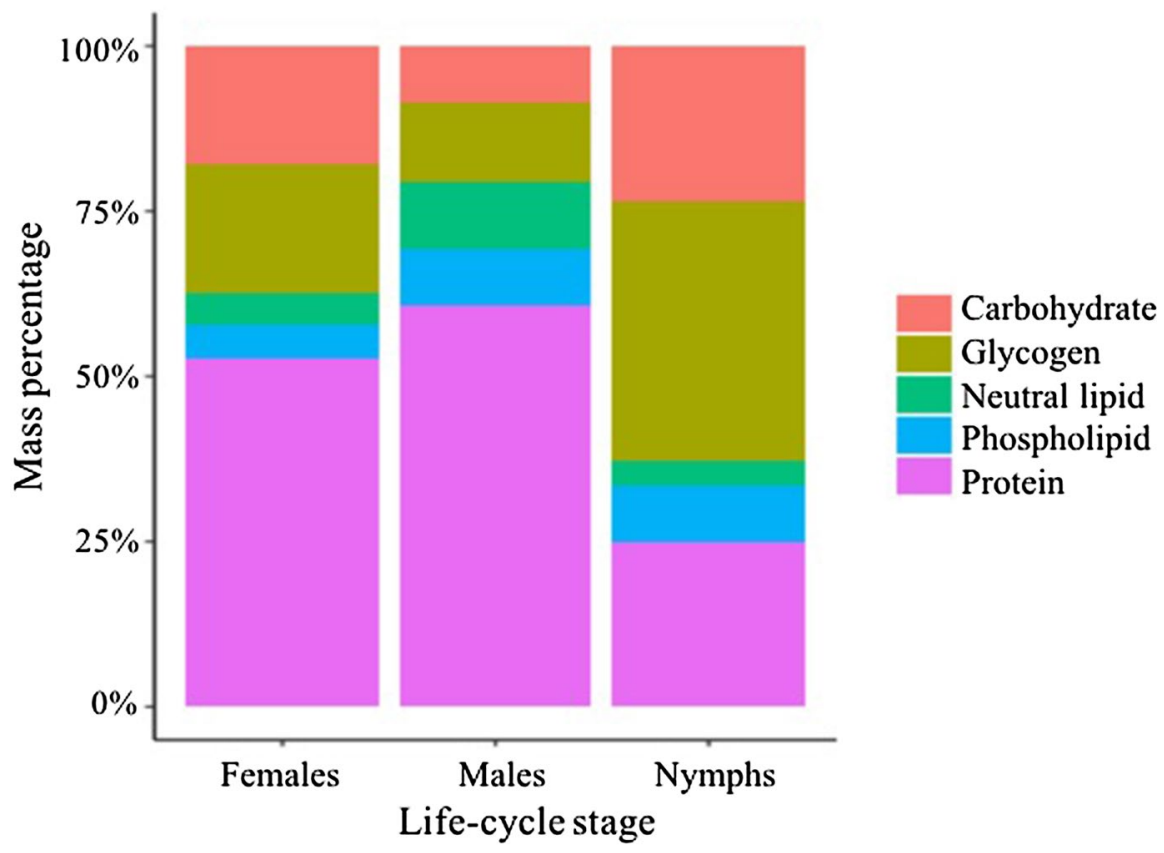

Fig. 4 The percentage mass for each metabolite category in individual Ixodes ricinus nymphs, males or females

comprehensively in ticks. The first analysis undertaken by the present study showed that there was no difference in the metabolite concentrations determined in either the ticks subjected to multiple analysis or ticks used for analysis of separate classes of metabolite. This was an essential initial step required to give confidence to the subsequent investigation, and to highlight the sensitivity and repeatability of the procedure. The ability to measure lipid, carbohydrate/glycogen simultaneously in individual ticks highlights the suitability of these methods for use in ecological and epidemiological studies. Overall, the results indicate that the spectrophotometric approaches appear to allow accurate and reproducible quantification of the entire range of the energetic reserves. This represents a considerable advance over the approaches used previously in ticks and the spectrophotometric approaches are able to deliver relatively rapid, inexpensive and reliable estimates of the total energetic budget.

The ticks used for the present study were collected by blanket dragging between March and May in southwest England when questing activity of nymphs and adults would have been expected to be at its peak. A range of stages of starvation would have been expected, with the population composed of cohorts that fed the previous year and either moulted the previous autumn or which overwintered or moulted in early spring prior to collection, depending on precisely when they had fed. The aim of this work was to evaluate the applicability of the analytical methods to ticks, rather than attempt to explain the cause or meaning of the differences observed, nevertheless two key trends were apparent. In adults, protein values were high and relatively greater than in nymphs whereas in nymphs $39 \%$ of the metabolites were composed of glycogen. In contrast in females, glycogen composed only $15 \%$ and in males $10 \%$ of the mass of metabolites. Carbohydrate was also relatively 
more abundant in nymphs and females than males. The relatively high protein levels in adults may be associated with reproduction, whereas the relatively high glycogen levels in nymphs and very high variability in carbohydrate values may indicate that the population of nymphs is divided into a cohort that moulted the previous autumn and a cohort that moulted in spring of the year they were collected. In contrast the adult population is largely composed of individuals that moulted the previous autumn, so lipid and carbohydrate values are relatively lower than in nymphs. At this stage these suggestions remain preliminary and, now that the spectrometric techniques have been validated, further long-term seasonal studies of metabolic profiles will allow changing metabolite patterns to be mapped more clearly to observed activity. The data show that the proportion of neutral lipids (stored lipids) was about half that of structural phospholipids in nymphs, and considerably higher in adults. Hence the data suggest that since the levels of triglyceride can vary significantly between life-cycle stages, when analysing lipid reserves, it is important to distinguish neutral lipids from structural phospholipids.

In summary, the current study has demonstrated that a complete energy budget for an individual tick can be quantified using spectrophotometric approaches, although it is still necessary to quantify protein separately. The expectation, therefore, is that the use of these techniques will facilitate further research using studies of tick metabolism to elucidate the seasonal pattern of feeding activity and physiological drivers leading to, for example, diapause (Raubenheimer et al. 2009). A more detailed understanding of the metabolic profile of ticks may also help in understanding the complex interaction between metabolism, pathogen infection, and transmission (Angelo et al. 2013, 2015; Herrmann et al. 2013).

Acknowledgements The authors are grateful to Dr Swaid Abdullah for advice and assistance throughout the laboratory work. The authors wish to thank colleagues in the Veterinary Parasitology and Ecology Group at University of Bristol for valuable comments on this manuscript and statistical advice. SA would also like to thank the Najran University for funding this work.

Open Access This article is licensed under a Creative Commons Attribution 4.0 International License, which permits use, sharing, adaptation, distribution and reproduction in any medium or format, as long as you give appropriate credit to the original author(s) and the source, provide a link to the Creative Commons licence, and indicate if changes were made. The images or other third party material in this article are included in the article's Creative Commons licence, unless indicated otherwise in a credit line to the material. If material is not included in the article's Creative Commons licence and your intended use is not permitted by statutory regulation or exceeds the permitted use, you will need to obtain permission directly from the copyright holder. To view a copy of this licence, visit http://creativecommons.org/licenses/by/4.0/.

\section{References}

Abdullah S, Davies S, Wall R (2018) Spectrophotometric analysis of lipid used to examine the phenology of the tick Ixodes ricinus. Parasites Vectors 11:523

Angelo IC, Golo PS, Perinotto WMS, Camargo MG, Quinelato S, Sá FA, Pontes EG, Bittencourt VREP (2013) Neutral lipid composition changes in the fat bodies of engorged females Rhipicephalus microplus ticks in response to fungal infections. Parasitol Res 112:501-509

Angelo IC, Tunholi-Alves VM, Tunholi VM, Perinotto WMS, Gôlo PS, Camargo MG, Quinelato S, Pinheiro J, Bittencourt VREP (2015) Physiological changes in Rhipicephalus microplus (Acari: Ixodidae) experimentally infected with entomopathogenic fungi. Parasitol Res 114:219-225

Arrese EL, Soulages JL (2010) Insect fat body: energy, metabolism, and regulation. Annu Rev Entomol 55:207

Arthur DR (1963) British ticks. CABI, Wallingford

Bradford MM (1976) A rapid and sensitive method for the quantitation of microgram quantities of protein utilizing the principle of protein-dye binding. Anal Biochem 72:248-254

Chown SL, Nicolson S (2004) Insect physiological ecology: mechanisms and patterns. OUP, Oxford 
Herrmann C, Voordouw MJ, Gern L (2013) Ixodes ricinus ticks infected with the causative agent of Lyme disease, Borrelia burgdorferi sensu lato, have higher energy reserves. Int J Parasitol 43:477-483

Hillyard PD (1996) Ticks of North-West Europe. SBF, Field Studies Council, Shrewsbury

Jennett AL, Smith FD, Wall R (2013) Tick infestation risk for dogs in a peri-urban park. Parasites Vectors 6:358

Kluck GEG, Cardoso LS, De Cicco NNT, Lima MS, Folly E, Atella GC (2018) A new lipid carrier protein in the cattle tick Rhipicephalus microplus. Ticks Tick-Borne Dis 9:850-859

Lighton JR, Fielden LJ (1995) Mass scaling of standard metabolism in ticks: a valid case of low metabolic rates in sit-and-wait strategists. Physiol Zool 68:43-62

Martins R, Ruiz N, Fonseca RND, Junior V, da Silva I, Logullo C (2018) The dynamics of energy metabolism in the tick embryo. Rev Bras Parasitol Vet. https://doi.org/10.1590/S1984-296120180051

Moraes J, Galina A, Alvarenga PH, Rezende GL, Masuda A, da Silva Vaz I Jr, Logullo C (2007) Glucose metabolism during embryogenesis of the hard tick Boophilus microplus. Comp Biochem Phys A 146:528-533

Needham GR, Teel PD (1991) Off-host physiological ecology of ixodid ticks. Annu Rev Entomol 36:659-681

Otronen M (1995) Energy reserves and mating success in males of the yellow dung fly, Scathophaga stercoraria. Funct Ecol 9:683-688

Pelosse P, Bernstein C, Desouhant E (2007) Differential energy allocation as an adaptation to different habitats in the parasitic wasp Venturia canescens. Evol Ecol 21:669-685

Randolph SE, Green RM, Hoodless AN, Peacey MF (2002) An empirical quantitative framework for the seasonal population dynamics of the tick Ixodes ricinus. Int J Parasitol 32:979-989

Raubenheimer D, Simpson SJ, Mayntz D (2009) Nutrition, ecology and nutritional ecology: toward an integrated framework. Funct Ecol 23:4-16

Rosendale AJ, Dunlevy ME, Fieler AM, Farrow DW, Davies B, Benoit JB (2017) Dehydration and starvation yield energetic consequences that affect survival of the American dog tick. J Insect Physiol 101:39-46

Sonenshine OE, Roe RM (2014) Biology of ticks, vol 1, 2nd edn. Oxford University Press, Oxford

Tatchell RJ (1971) Electrophoretic studies on the proteins of the haemolymph, saliva, and eggs of the cattle tick, Boophilus microplus. Insect Biochem 1:47-55

Uspensky I (1995) Physiological age of ixodid ticks: aspects of its determination and application. J Med Entomol 32:751-764

Van Handel E (1965) Estimation of glycogen in small amounts of tissue. Anal Biochem 11:256-265

Van Handel E (1985a) Rapid determination of glycogen and sugars in mosquitoes. J Am Mosq Control Assoc 1:299-301

Van Handel E (1985b) Rapid determination of total lipids in mosquitoes. J Am Mosq Control Assoc $1: 302-304$

Walker A, Bouattour A, Camicas J-L, Estrada-Peña A, Horak IG, Latif AA, Pegram RG, Preston PM (2014) Ticks of domestic animals in africa: a guide to identification of species. Bioscience Reports, Edinburgh

Walker AR (2001) Age structure of a population of Ixodes ricinus (Acari: Ixodidae) in relation to its seasonal questing. Bull Entomol Res 91:69-78

Weiss BL, Kaufman WR (2004) Two feeding-induced proteins from the male gonad trigger engorgement of the female tick Amblyomma hebraeum. Proc Natl Acad Sci USA 101:5874-5879

Williams JP, Sauer JR, McNew RW, Hair JA (1986) Physiological and biochemical changes in unfed lone star ticks, Amblyomma americanum (Acari: Ixodidae) with increasing age. J Med Entomol 23:230-235

Xavier MA, Tirloni L, Pinto AFM, Diedrich JK, Yates JR, Gonzales S, Farber M, Vaz ID, Termignoni C (2019) Tick Gene's organ engagement in lipid metabolism revealed by a combined transcriptomic and proteomic approach. Ticks Tick-Borne Dis 10:787-797

Publisher's Note Springer Nature remains neutral with regard to jurisdictional claims in published maps and institutional affiliations. 